\title{
Teknokultura
}

ISSNe: $1549-2230$

http://dx.doi.org/10.5209/TEKN.57592

\section{Educación Artística y transformación social en el contexto de las Humanidades Digitales ${ }^{1}$}

\author{
Rafael Marfil-Carmona²
}

Recibido: 9 de octubre de 2017 / Revisado: 6 de diciembre de 2017 / Aceptado: 18 de diciembre de 2017. Open peer reviews

Resumen. Las artes visuales y audiovisuales tienen una destacada presencia en la Red. Hoy día resulta imposible desarrollar una educación artística que no tenga en cuenta la influencia de la cultura digital. En el siglo XXI la aproximación didáctica al arte requiere de la implementación de procesos propios de la alfabetización mediática, visual y audiovisual. Confluyen, por tanto, Educación Mediática y Artística para asegurar la transformación individual y social. Este propósito se enmarca en lo que hoy se denominan Humanidades Digitales, centradas en el empoderamiento ciudadano y posible a través de procesos de aprendizaje y creatividad. Es urgente la adaptación de esta actividad y la reflexión en torno a la realidad contemporánea de la cultura digital y de la innovación, artística y educativa a través de los medios tecnológicos y de las pantallas. En este texto se proponen algunas bases conceptuales que, desde un punto de vista interdisciplinar, permitan abordar una educación artística que tenga en cuenta las características de una sociedad prosumidora, inmersa en procesos de activa participación en redes y tendente a la infoxicación que produce la creación y difusión masiva de imágenes. Además, la transición desde un modelo educativo y artístico eminentemente manual, a una nueva realidad basada en la tecnología y el factor relacional, debe considerarse como una evolución construccionista que permita implementar un enfoque integrador de viejas y nuevas perspectivas, persiguiendo siempre el compromiso por consolidar la creatividad y comprensión artística como factor para el desarrollo humano y la transformación social, factores imprescindibles para una ciudadanía crítica.

Palabras clave: artes visuales; cultura digital; cultura visual; factor relacional.

\section{[en] Artistic Education and social transformation in the context of Digital Humanities}

\begin{abstract}
The visual and audiovisual arts have an important presence on the Internet. For this reason, it is currently impossible to develop an Arts Education that does not take into account the relevance of digital culture. In the 21 st century, the didactic approach to art requires the implementation of media literacy, visual and audiovisual processes. Media and Artistic Education come together to ensure individual and social transformation. Digital Humanities has much to do with this purpose. They are centred on the empowerment of citizens, made possible through learning and creativity processes. There is an urgent need to adapt Arts Education to digital culture and innovation, artistic and educational, through technological media and screens. This text proposes some conceptual bases that, from an interdisciplinary point of view, allow artistic education that takes into account the characteristics of a prosumer society. This society is immersed in processes of active participation in Social Media, but also tends to info-xication that produces the mass creation and diffusion of images. The transition

1 Trabajo realizado en el marco del proyecto "Métodos artísticos y visuales de Investigación, Innovación Educativa e Intervención Social”, HAR2016-76353-R, del Programa Estatal de I+D+i Orientada a los Retos de la Sociedad del Ministerio de Economía y competitividad del Gobierno de España.

2 Universidad de Granada (España)

E-mail: rmarfil@ugr.es
\end{abstract}


from an educational and artistic model, eminently manual, to a new reality based on technology and the relational factor, must be considered as a constructionist evolution that allows implementing an integrating approach of old and new approaches. The objective is to consolidate creativity and artistic understanding as a factor for human development and social transformation, essential factors for critical citizenship.

Keywords: digital culture; relational factor; visual arts; visual culture.

Sumario: 1. Introducción. 2. Antecedentes y estado de la cuestión. 3. Arte, Educación y Humanidades digitales para la transformación social. 4. Consideraciones finales. 5. Referencias.

Cómo citar: Marfil Carmona, R. "Educación Artística y transformación social en el contexto de las Humanidades Digitales”: Teknokultura, vol. 15 (1) 2018, pp. 139-150.

\section{Introducción}

El arte, como otros ámbitos de la actividad humana y social, se ha transformado. De forma paralela, la educación también. Aunque gran parte de la actividad artística actual no requiere de la utilización de los medios digitales, cada vez es más habitual encontrar creaciones e iniciativas artísticas que, desde las posibilidades que permite Internet, plantean nuevos procesos para la creación y el aprendizaje. Algunas bases de los planteamientos pedagógicos que debe abordar esta nueva realidad se encuentran en las teorías que ya contemplaban la conexión entre educación y comunicación a principios del siglo XX, sobre todo por la mutua transformación e implicación social de los agentes implicados:

No solo la vida social es idéntica a la comunicación, sino que toda comunicación (y por tanto toda vida social auténtica) es educativa. Ser un receptor de una comunicación es tener una experiencia ampliada y alterada. Se participa en lo que otro ha pensado y sentido, en tanto que de un modo restringido o amplio se ha modificado la actitud propia. Tampoco deja de ser afectado el que comunica. Realizad el experimento de comunicar, con plenitud y precisión, alguna experiencia a otro, especialmente si es algo complicado, y encontraréis que ha cambiado vuestra propia actitud respecto a vuestra experiencia. (Dewey, 1916/1998, pp. 16-17)

La denominada Sociedad Red (Castells, 1996/1997) es, en sí misma, la manifestación más evidente de ese permanente proceso de comunicar y, por tanto, de educar y aprender. En la segunda década del siglo XXI, podemos seguir definiendo la sociedad contemporánea como "iconosfera", término empleado por Gilbert Cohen-Séat (1959) para describir el entorno visual en el que tenía una especial preeminencia el cine (p. 8), ante el que Román Gubern (1987) planteaba la necesidad de una mirada crítica, ya que las imágenes que conforman ese ecosistema visual "no son inocentes ni neutras" (p. 405).

Más allá de la mirada crítica a lo que se puede seguir definiendo como "civilización de la imagen" (Fulchignoni, 1964), es crucial que esa adaptación de la docencia artística sea consciente de la dimensión social de la cultura digital y de la imprescindible implicación en procesos transformadores y emancipadores de la ciudadanía, 
que ha tomado protagonismo a través del uso de las redes sociales. En este sentido, lo artístico confluye e hibrida con lo mediático.

La enseñanza del arte en contextos digitales entronca con las bases fundacionales de la Educación Mediática, centrada en el poder emancipador del acceso a los medios de difusión (De Oliveira, 2011; Kaplún, 1998; Orozco, 1994), siguiendo modelos pedagógicos de fuerte compromiso social y crítico ante el sistema (Escaño y Villalba, 2009; Freire, 1970/2005 y 1979/2009; McLaren y Kincheloe, 2008). El arte en la cultura digital encuentra, de forma natural, una esencia centrada en la vertiente mediática y en el compromiso con la transformación social, en la que es posible que el colectivo docente descubra su papel de "agitador intelectual" que haga posible que el alumnado "... sea capaz de crear su propio conocimiento crítico" (Cuesta, 2016, p. 289). Si la conexión con la dimensión mediática está clara, la conexión con el activismo en red será el siguiente paso, ya que las competencias digitales han complementado a las audiovisuales en la acción educomunicativa con unas dimensiones bien definidas (Ferrés y Piscitelli, 2012).

Esta conexión entre los medios de masas y el arte se refuerza si tenemos en cuenta que el contenido esencial de los medios digitales pasa por la creación visual y audiovisual. Además, gran parte de la actividad artística está dirigiendo su foco hacia el propio discurso tecnológico y mediático. Su enseñanza va más allá de la dimisión individual de la denominada experiencia estética, si no que suma una constante implicación en procesos de hipermediaciones (Scolari, 2008). Se desarrollan mediante una base relacional que implica, en sí misma, la creación y percepción artística (Dewey, 1980/2008, p. 58), manteniendo las bases esenciales de esta actividad. Considerando las humanidades digitales como una "... 'transdisciplina' portadora de los métodos, dispositivos y perspectivas heurísticas relacionadas con procesos de digitalización en el campo de las Ciencias Humanas y Sociales" (ThatCamp, 2010), este ámbito no deja de ser, actualmente, un entorno para lo artístico que está diseñado desde una nueva "poética de la colaboración" (Pons, 2014, p. 129), propia del medio. Esas opciones de interacción social y horizontalidad marcan una clara línea de trabajo dirigida hacia el entorno humano, tanto individual como colectivo.

Las transformaciones en el proceso de percepción, acceso, creación, difusión y aprendizaje, pasan por el cambio del concepto de autoría en algunos casos, en la que lo individual se diluye en beneficio de procesos colaborativos, pero también ofrece una oportunidad a aquellas personas que, con su acceso a los medios digitales, tienen alguna inquietud relacionada con la construcción y transformación social. La Educación Artística, hasta el momento, no se ha adaptado en la plenitud debida a esta nueva realidad. Por ello, en este texto se proponen algunas bases de actuación que integran lo educativo, lo artístico y el compromiso social. Este último, no solo es el resultante del uso o el estudio de las herramientas y los medios digitales, sino de focalizar el esfuerzo educativo e investigador en el original compromiso de este ámbito interdisciplinar con y para el desarrollo humano (Gardner, 1994).

\section{Antecedentes y estado de la cuestión}

La segunda mitad del siglo XX consolidó un nuevo modelo de Educación Artística, más social y abierto a la comprensión del contexto, lejano del academicismo del 
XIX. La propia orientación del currículo desde la segunda mitad del pasado siglo, daba cabida, en alguno de sus enfoques, a la posibilidad de que el estudiante:

...centre su atención en la utilidad del arte en la sociedad a través del tiempo, en las valoraciones que hacen los artistas sobre el mundo -incluyéndose a sí mismos- a través de su obra y en la relación entre la sociedad y el contenido y la forma de las obras de arte. (Eisner, 1972/1991, p. 154)

De forma previa, se había apostado por la autoexpresión de una creatividad que dignificara la espontaneidad infantil (Lowenfeld, 1958). Por lo tanto, se puede afirmar que la mirada hacia lo humano y lo social ha estado presente en la enseñanza del arte desde el siglo XX. Las consecuencias de esa acción educativa, es decir, las propias creaciones, no solo expresan emociones y sentimientos, sino que representan, en sí mismas, una forma de pensamiento (Marín Viadel, 2003, p. 34), que puede convertirse en investigación de rango académico:

(...) de tal modo que, en lugar de considerar la actividad científica como contradictoria y opuesta a la actividad artística, lleguen a verse no solo como complementarias, sino también como equivalentes en cuanto a los logros cognoscitivos que pueden alcanzarse con unas y otras. (Marín Viadel, 2011, p. 226)

Tanto el enfoque de la enseñanza de lo artístico como un fenómeno espontáneo, basado en la libre expresión (Lowenfeld, 1958; Lowenfeld y Brittain, 1987/2008), como desarrollos más recientes, que han incidido en la aportación intelectual e investigadora de las propias imágenes y creaciones artísticas (Roldán y Marín Viadel, 2012), el profundo sentido humano y emancipador de esta actividad ha tenido siempre presente su dimensión social, una faceta que se puede desarrollar de forma mucho más efectiva en la época de las redes sociales.

En la vertiente educomunicativa de esa transformación, por ejemplo, se ha dejado constancia del cambio de paradigma de una sociedad activa y participativa, donde las personas no solo visitan o consultan los contenidos, sino que crean y forman parte de todo el proceso sin limitarse a recepcionar el mensaje. Por su parte, las escuelas de arte siempre habían estado instaladas en ese enfoque creativo. Se trata de lo que, a finales de los años 70 del siglo XX, se denominó, de forma premonitoria, prosumer (Toffler, 1979) o EMIREC (Cloutier, 1975). El rol activo es la verdadera transformación de esa cultura participativa, en la que todavía hay muchos procesos por asimilar y clarificar:

Más que hablar de productores y consumidores mediáticos como si desempeñasen roles separados, podríamos verlos hoy como participantes que interaccionan conforme a un nuevo conjunto de reglas que ninguno de nosotros comprende del todo. No todos los participantes son creadores iguales. Las corporaciones, e incluso los individuos dentro de los medios corporativos, ejercen todavía un poder superior al de cualquier consumidor individual o incluso al del conjunto de consumidores. Y unos consumidores poseen mayores capacidades que otros para participar en esta cultura emergente. (Jenkins, 2006/2008, p. 15) 
Desde el punto de vista creativo son cada vez más numerosas las experiencias que dan cabida al video social y a la creación colectiva, con aplicaciones recientes a contextos educativos como la Educación Superior (Ornellas, 2013) o el desarrollo de un cine basado en prácticas horizontales que destacan por la ausencia de autoría (Sedeño Valdellós, 2012). No es necesario acudir a experiencias marginales o anecdóticas para comprobar cómo la Red está transformando la nueva forma de comunicar y educar en lo que tiene que ver con la imagen. Lo descrito es un proceso habitual y masivo. Basta, por ejemplo, con valorar los patrones básicos de funcionamiento de una red social audiovisual como YouTube:

En cualquier caso, el modelo de funcionamiento de YouTube quiebra de forma radical la dinámica de los medios tradicionales imponiendo una nueva configuración de las relaciones entre medios tradicionales y productores independientes, una mayor interacción dialógica entre creadores mediáticos y usuarios (potencialmente creadores también), la experimentación con nuevos formatos comunicativos audiovisuales (¿quizá un nuevo estatuto de la imagen?) y una renovada relación entre comunicadores y tecnologías. (García Marín, Aparici y Rubido Crespo, 2017, p. 85)

Durante los últimos años ha surgido un interés, desde el ámbito académico, en torno a los desarrollos artísticos relacionados con Internet y las redes sociales. En este sentido, las obras de referencia en la materia deben recapitular en torno a las décadas de evolución que ha experimentado la presencia del arte en estos nuevos medios, partiendo del denominado Net Art, vigente en la actualidad y que evoluciona adaptándose a los cambios tecnológicos, reflexionando de forma crítica sobre ellos. Ya en los años 90 del pasado siglo, el Net Art se definía como un término “... creado por la disfunción de una pieza de software y utilizado originalmente para describir la actividad artística y comunicativa en Internet [...] Los net.artistas buscaban quebrar las disciplinas autónomas y las anticuadas clasificaciones impuestas a algunas prácticas artísticas" (Bookchin y Shulgin, 1999, p. 1).

En la Red, la conexión crítica está presente desde el inicio, por lo que no era difícil llegar nuevo pensamiento social y las formas de poder en el sistema-red que permiten lo que pueden denominarse, según Juan Martín Prada, "tecnologías de la disensión" (2015, p. 69), en cuya consideración surgen términos como el hacktivismo, vinculados estrechamente con el arte. Este concepto une la actividad hacker, relacionada con el uso de las herramientas digitales, con un alto dominio del software y del código, pero no en su acepción delictiva, sino en la variante conceptual del compromiso y la acción social, es decir, en la actividad vinculada a la ayuda a los demás y al cumplimiento de unas estrictas normas de comportamiento ético (Denning, 1990, p. 653).

En realidad, gran parte de la actividad reivindicativa gira en torno a un proceso de creación, representación, difusión y percepción. En esa confluencia de lo social, lo ético, lo artístico y lo mediático, siempre está presente la distancia y la confusión entre lo virtual y lo "real", en un proceso que exterioriza nuestras pulsiones más internas, individuales y colectivas, liberándonos:

Considerar el hacktivismo como actividad artística en sí misma presupondría un rechazo a cualquier división o separación entre el ámbito de lo imaginario y de lo real 
en el campo de los medios, entre las referencias políticas que la propuesta artística contendría y las pretensiones de una efectividad política "real", con lo que el concepto "arte" en ese contexto de actuaciones vendría a ser identificable no tanto con lo que aporta esa acción como lenguaje o expresión, sino con el lenguaje que libera o ayuda a liberar. Se operaría así cierta transposición entre la tradicional idea del arte como expresión de lo "reprimido" en el individuo y otra conceptualización de la idea del arte como la expresión de lo "reprimido" en el ámbito social. (Martín Prada, 2015, p. 88)

En el desarrollo de la Educación Artística se asimilan inicialmente las bases de la representación visual como lenguaje (Acaso, 2006; Álvarez-Rodríguez, 2003) y las fronteras con la realidad, que hacen imprescindible la implementación de una "cultura de la sospecha", sobre todo ante los contenidos mediáticos (Acaso, 2007; Ferguson, 2004/2007). El estímulo de una mirada crítica incide en esa frontera de lo real y su representación en lo que tiene que ver con la enseñanza de la imagen digital (Aparici y García Matilla, 2008). Internet ha hecho crecer exponencialmente el número de imágenes consumidas cada día, en un proceso cuyo riesgo principal es la infoxicación, es decir, la incertidumbre de un mundo de sobreabundancia, donde es necesaria la información trascendente y contextualizada por los profesionales de la información (Franco Rodríguez y Gértrudix Barrio, 2015, p. 157). Con la imagen y lo artístico se hace especialmente patente este fenómeno, sobre todo por la actividad creadora, que es una constante en la sociedad digital

Es evidente también, en lo relacionado con el arte, la dimensión mediática que le confiere la adaptación de esa mirada al entorno digital, aportando activamente en lo que, más que representación, es "construcción" de la realidad:

La producción de un mensaje conlleva construir una nueva realidad, al punto de que podemos hablar de una realidad inventada, de una realidad desde donde se crean metáforas y grandes relatos sobre la sociedad y el mundo. (Aparici, 2010, p. 15)

Uno de esos grandes relatos que legitiman el saber y nos ayudan a aprehender el mundo, aplicando el concepto empleado por la teoría de la Posmodernidad (Lyotard, 1979/2008, p. 63), es el artístico. Como ejemplo, la creación visual se hace patente en el día a día de nuestras pantallas, haciendo válida la "teoría del reflejo" cómo búsqueda de veracidad, es decir, de cientifismo y positivismo, asociado inicialmente a la palabra (Rorty, 1989) y, posteriormente, a la imagen, en lo que se puede denominar un "giro pictorial". Si "... la sociedad es un texto" (Mitchell, 1994/2009, p. 19), su actividad y representación en Internet también. Un gran texto visual, multimedia e hipermedia.

La reflexión del uso que se hace en Internet desde la Educación Artística, lleva también a cuestionar el papel de la creación humana y de la máquina en lo que se denomina inteligencia artificial. Una realidad que va siendo, cada vez, más cercana (Escaño, 2010, p. 142). A esa visión crítica, se unen diversas investigaciones recientes centradas en el aprovechamiento de las tecnologías como recurso para la mejora de la Educación Artística, con un carácter menos social y más centrado en la eficacia formativa, como las mejoras en la evaluación de formadores (Salido López, 2015). Destaca especialmente, sobre todo por el uso de las posibilidades organizativas y dialógicas, el establecimiento de redes sociales específicas para el profesorado de 
Educación Artística (Saura Pérez, 2013a y 2013b). Sin embargo, a pesar de las aproximaciones a la cultura digital, el tratamiento del arte desde el punto de vista educativo está todavía por desarrollar, especialmente en las implicaciones de conexión y transformación social. Es importante señalar, en ese sentido, que no debe abandonar los procesos táctiles y de percepción manual. No es un proceso excluyente, sino una suma de contextos de creación y aprendizaje.

\section{Arte, Educación y Humanidades digitales para la transformación social}

Las conexiones de la Educación Artística y el compromiso social son tantas como las que pueden generar actividades tan amplias y diversas como el arte y la educación. Un ejemplo es la reflexión en torno a las imágenes generadas por las propias ONG a través de la publicidad solidaria (Marfil-Carmona, 2015; Roldán, 2012), además de innumerables referencias que abordan la transformación individual en actividades enmarcadas en Arteterapia (Dalley, 1984/1987; Klein, 2006; López Fernández-Cao, 2011), junto al fomento de valores y la lucha contra la discriminación, en cuestiones concretas como la diversidad sexual (Huerta, 2014), entre otras temáticas que responden a una inquietud de integración social.

Lo digital marca un nuevo entorno en el que confluyen diferentes presencias de lo artístico. Por un lado, podemos entender una página web o las redes sociales como meros contenedores de imágenes o contenidos multimedia en los que el arte, lo educativo o ambas cuestiones tienen un papel determinante. Sin embargo, por inocente que parezca el hecho de facilitar el acceso a la obra, cualquier sistema de almacenamiento, exhibición o análisis no es nunca desinteresado o carente de intenciones, respondiendo a una consideración específica de lo artístico. Este uso, que se podría denominar 1.0, confluye en la infoxicación de imágenes artísticas, tal y como se ha comentado. Muchas de ellas, reinterpretadas y remezcladas, en una clara bifurcación del concepto de "mal de archivo", apuntado por Derrida (1997).

Dando un paso más, la web 2.0 y 3.0 establece un nuevo entorno discursivo en el que la creación artística tiene unas características específicas. Siguiendo precisamente a Howard Gardner (1990/1994), “... es probable que cada una de las hebras del conocimiento artístico experimente su propia trayectoria característica de desarrollo y no necesariamente tienen que ser consistentes unas con otras" (p. 74). En este sentido, las Humanidades Digitales deben considerar lo específico del entorno digital como medio para la acción y el aprendizaje artísticos, por estar situados en la confluencia conceptual de una multiplicidad de ángulos complementarios que, precisamente, son un campo idóneo para el estímulo de las inteligencias múltiples (Gardner, 1993/2011), entre las que destaca la creadora (Marina, 1993), superando los modelos educativos unidireccionales y ortodoxos. Hay experiencias que, además de difundir una web principal o un blog, establecen un activo diálogo con las personas interesadas a través de la red, como el caso de Communiars o la página en Facebook del proyecto solidario Bombearte-Honduras, proyectos de cooperación a través de la Educación Artística realizados por las universidades de Sevilla y Granada respectivamente ${ }^{3}$.

Información disponible en https://communiars.wordpress.com/y https://www.facebook.com/Arte-Para-Aprender-Honduras-Bombearte-1735071823444702/ [2017, 1 de septiembre]. 
Encontramos, de esta forma, una cultura visual contemporánea en la que lo digital acoge un "activismo visual", con ejemplos en el uso de redes sociales específicas dedicadas a la fotografía, como Instagram, lo que implica un compromiso constante en el día a día en la aportación de imágenes, acogiendo diversidad de enfoques y propuestas creativas. Se trata, en resumen, de aprender a ver el mundo para, posteriormente, transformarlo:

El activismo visual es la interacción de píxeles y acciones para crear cambios. Los píxeles son el resultado visible de todo lo producido por un ordenador, desde palabras creadas por un procesador de textos hasta todo tipo de imágenes, sonidos y vídeos. Las acciones son cosas que hacemos con estas formas culturales para crear cambios pequeños o grandes, desde una acción política directa hasta una representación (en la vida cotidiana o en un teatro), una conversación o una obra de arte. Una vez que hemos aprendido a ver el mundo, hemos dado uno de los pasos requeridos, pero solo uno de ellos. Ahora se trata de transformarlo. (Mirzoeff, 2016, p. 260)

Integrado en la amplitud de ese activismo a través de lo visual, se desarrolla una línea de actuación basada en la idea del procomún, lo que supone un concepto transformador de una idea tan estática socialmente como el mercado:

Hablar de procomún es decir que el dinero ya no es el único valor importante: pertenecer a una comunidad con la que se comparten valores morales y objetivos sociales puede ser una potente fuerza creativa por derecho propio. Resulta que la libertad significa algo más que maximizar la utilidad económica propia. (Bollier, 2003, p. 4)

La línea de trabajo que pretenda unir arte y educación en la Red pasa inevitablemente por establecer conexiones con la Educación Mediática, desde ese aprovechamiento de la intercreatividad (Escaño, 2013) y de un conocimiento que "... implica una pluralidad social inherente en su producción que le hacen ser un hecho compartido, distribuido y comunicable para su desarrollo" (Escaño, 2017, p. 241). Desde el inicio de tecnología que hace posible esta línea de trabajo, han sido numerosas experiencias y laboratorios relacionados con cultura libre y recursividad (Estalella, Rocha y Lafuente, 2017, p. 35), en ámbitos en los que el arte, la creatividad y la cultura tienen un papel destacado.

Todo este proceso es posible gracias al factor relacional (Marta-Lazo y Gabelas Barroso, 2016), es decir, a las posibilidades de conexión e interconectividad que, desde la base del elemento humano, se lleva a cabo a través de las tecnologías actuales. En lo concerniente a la Educación Artística, hay que señalar que la gran mayoría de actividades realizadas en este sentido se basan en la difusión de lo que tiene lugar de forma física y presencial en determinados lugares del mundo. Se difunden las artes clásicas en la Red, pero no tanto el uso directo de las posibilidades de Internet a la hora de implementar procesos didácticos y creativos en torno al arte como vía para el cambio social. Por ello, las líneas de trabajo señaladas se recogen en algunas investigaciones que empiezan, además, a generar teoría en torno a la Educación Artística 
en la Cultura Digital, aunque es indudable que se trata, fundamentalmente, de una adaptación progresiva, de lo presencial a lo virtual, que debe recoger las fortalezas de lo viejo y lo nuevo, aprovechando los recursos que ofrece la Red para una buena Educación Artística. Es una evolución en la que se deben de acumular e integrar posibilidades para la enseñanza del arte.

\section{Consideraciones finales}

Hay mucho trabajo por hacer en las implicaciones que tiene el arte y la educación en la Red, fundamentalmente por la potencialidad de Internet para asegurar una inmersión y participación activa a través de procesos enfocados al desarrollo humano y la transformación individual y social. Utilizando correctamente la tecnología no es difícil conseguir la inmersión real y activa de una sociedad prosumidora. En el ámbito de las Humanidades Digitales, la Educación Artística, por su dimensión interdisciplinar, está llamada liderar ese tipo de procesos centrados en el compromiso social, respondiendo así a lo que siempre ha sido una vocación emancipadora. Aprender arte de cualquier otra forma sería una formación vacía, centrada en la técnica y en el puro formalismo estético. Se trata de una actividad que debe tener fondo y perseguir la transformación individual y social.

En la imprescindible integración de la didáctica de las artes visuales y la cultura digital. En esa línea de trabajo, resulta difícil diferenciar entre Educación Mediática y Artística, ya que cualquier proceso de creación visual pasa, inevitablemente, por procedimientos de diseño o representación mediante dispositivos tecnológicos, cuyos resultados son susceptibles de ser difundidos de forma masiva a través de las pantallas. Al menos en la mayor parte de los casos.

Sin embargo, no es tan interesante para el futuro inmediato de las artes visuales la consideración de las redes sociales como repositorio o mera vía promocional, sino la incidencia en los procesos de acción colaborativa. Su aprovechamiento gracias a características como la ubicuidad y el factor relacional, hace posible el aprendizaje colaborativo y la creación horizontal. Si se logran implementar de forma correcta, el grado de interacción y transformación social es notable, un cambio que viene acompañado de factores positivos que deberían favorecer la inclusión individual y el cambio social.

Si bien las experiencias artísticas en la Red, como el caso del Net Art, pueden ser un punto de partida, actualmente sigue habiendo mucho camino por recorrer, teniendo presente siempre el sentido humano y transformador; huyendo de la creación estética vacía y, en definitiva, favoreciendo el empoderamiento de una ciudadanía crítica a través de la comprensión, el aprendizaje y la creación.

\section{Referencias}

Acaso, M. (2006). El lenguaje visual. Barcelona: Paidós.

Acaso, M. (2007). Esto no son las torres gemelas Cómo aprender a leer la televisión y otras imágenes (2a. ed.). Madrid: Catarata.

Álvarez-Rodríguez, D. (2003). Esto no es una pipa. En R. Marín Viadel (coord), Didáctica de la Educación Artística (pp. 359-393). Madrid: Pearson. 
Aparici, R. (2010). La construcción de la realidad. En R. Aparici (coord.), La construcción de la realidad en los medios de comunicación (pp. 11-22). Madrid: UNED.

Aparici, R. y García Matilla, A. (2008). Lectura de imágenes en la era digital. Madrid: Ediciones de la Torre.

Bollier, D. (2007). El redescubrimiento del procomún [en línea] Disponible en http:// biblioweb.sindominio.net/telematica/bollier.pdf [2017, 4 de septiembre]

Bookchin, N. \& Shulgin, A. (1999). Introduction to Net.Art (1994-1999), [En línea]. Easylife. org. Disponible en https://goo.gl/Cwjfek [2017, 4 de septiembre]

Castells, M. (1997). La era de la información. Economía, sociedad y cultura. (Trads. C. Martínez Gimeno y J. Alborés) (Vol. I: La sociedad red). Madrid: Alianza (Original en inglés, 1996).

Cloutier, J. (1975). L'Ere d'EMEREC ou la communication audio-scripto-visuelle. Montreal (Canadá): Les Presses de l' Université de Montreal.

Cohen-Séat, G. (1959). Problèmes actuels du cinéma et de l'information visuelle I Problèmes sociaux. Paris: Presses Universitaires de France.

Cuesta, J. (2016). Investigación y desarrollo de buenas prácticas en educación plástica y visual. En M. Andueza, A.M. Barbero, M. Caeiro, A. da Silva, J. García, A. González, A. Muñiz y A. Torres, Didáctica de las artes plásticas y visuales en Educación Infantil (pp. 281-303). Logroño: Universidad Internacional de La Rioja (UNIR).

Dalley, T. (1987). El arte como terapia (Trad. J. Andrés Iglesias). Barcelona: Herder (Original en inglés, 1984).

De Oliveira Soares, I. (2011). Educomunicação: O conceito, o profissional, a aplicação (2a. ed.). São Paulo (Brasil): Ed. Paulinas.

Denning, D. (1990). Concerning Hackers Who Break Into Computer Systems, [en línea]. En 13th National Computer Security Conference, octubre de 1990 (pp. 653-664), Whasington D.C.: USA. Disponible en https://goo.gl/6HJPW9 [2017, 1 de septiembre]

Dewey, J. (1998). Democracia y educación. Una introducción a la filosofía de la educación (3 ed). (Trad. L. Luzuriaga). Madrid: Morata (Original en inglés, 1916).

Derrida, J. (1997). Mal de archivo. Una impresión freudiana (Trad. P. Vidarte). Madrid: Trotta (Original en francés, 1995)

Dewey, J. (2008). El arte como experiencia (Trad. J. Claramonte). Barcelona: Paidós (Original en inglés, 1980).

Eisner, E.W. (1991). Educar la visión artística (Trad. D. Cifuentes Camacho). Barcelona: Paidós (Original en inglés, 1972).

Escaño, C. (2010). Hacia una educación artística 4.0. Arte, Individuo y Sociedad, 22(1), 135-144. Disponible en https://revistas.ucm.es/index.php/ARIS/article/view/ ARIS1010110135A [2017, 4 de septiembre].

Escaño, C. (2013). EDUCACIÓN MOVE COMMONS. Procomún, Cultura Libre y acción colaborativa desde una pedagogía crítica, mediática y e-visual. Arte, individuo y sociedad, 25(2), 319-336. http://revistas.ucm.es/index.php/ARIS/article/view/ARIS1010110135A

Escaño, C. (2017). Bienes comunes del conocimiento: Una propuesta de desarrollo histórico del procomún digital. Opción, (82), 239-263. Disponible en http://www. produccioncientifica.luz.edu.ve/index.php/opcion/article/view/22845

Escaño, C. y Villalba, S. (2009). Pedagogía crítica artística. Sevilla: Diferencia.

Estalella, A., Rocha, J. y Lafuente, A. (2013). Laboratorios de procomún: experimentación, recursividad y activismo. Tecnokultura, 10(1), 21-48. Disponible en http://revistas.ucm. es/index.php/TEKN/article/view/48053/44930 [2017, 5 de septiembre]. 
Ferrés, J. y Piscitelli, A. (2012). La competencia mediática: propuesta articulada de dimensiones e indicadores. Comunicar, 19(38), 75-82. http://dx.doi.org/10.3916/C382012-02-08

Ferguson, R. (2007). Los medios bajo sospecha. Ideología y poder en los medios de comunicación (Trads. O. Castillo, R. González del Solar, G. Ubaldini, A Bixio, I. Olgallar y M. Polo). Barcelona: Gedisa (Original en inglés, 2004).

Franco Rodríguez, R. y Gértrudix Barrio, M. (2015). Infoxicación: implicaciones del fenómeno de la profesión periodística. Revista de Comunicación de la SEECI, (38), 141181. http://dx.doi.org/10.15198/seeci.2015.38.141-181

Freire, P. (2005). Pedagogía del oprimido (2a. ed.). (Trad. Jorge Mellado). México: Siglo XXI (Original en portugués, 1970)

Freire, P. (2009). La educación como práctica de la libertad (Trad. L. Ronzoni). Salamanca: Siglo XXI (Original en portugués, 1969).

Fulchignoni, E. (1964). La moderna civiltà dell'immagine. Roma: A. Armando.

García Marín, D., Aparici, R. y Rubido Crespo, S. (2017). Modelos de comunicación horizontal. En R. Aparici y D. García Marín, Comunicar y educar en el mundo que viene (pp. 71-87). Barcelona: Gedisa.

Gardner, H. (1994). Educación artística y desarrollo humano (Trad. F. Meler-Orti). Barcelona: Paidós (Original en inglés, 1990).

Gardner, H. (2011). Inteligencias múltiples. La teoría en la práctica (Trad. M. T. Melero Nogués). Madrid: Paidós. (Original en inglés, 1993).

Gubern, R. (1987). La mirada opulenta: Exploración de la iconosfera contemporánea. Barcelona: Gustavo-Gili.

Huerta, R. (2014). La Educación Artística como motor de cambio social. Cuadernos de pedagogía, (449), 48-50.

Jenkins, H. (2008). Convergence culture: La cultura de la convergencia de los medios de comunicación (Trad. P. Hermida Lazcano). Barcelona: Paidós (Original en inglés, 2006).

Kaplún, M. (1998). Una pedagogía de la comunicación. Madrid: Ediciones de la Torre.

Klein, J.P. (2006). Arteterapia: una introducción (Trad. C. Homar). Barcelona: Octaedro.

López Fernández-Cao, M. (2011). Memoria, ausencia e identidad. El arte como terapia. Madrid: Eneida.

Lowenfeld, V. (1958). El niño y su arte. (Trad. A. M. Ghioldi) Buenos Aires: Kapelusz.

Lowenfeld, V. y Lambert Brittain, W. (2008). Desarrollo de la capacidad intelectual y creativa (Trad. M. Orive). Madrid: Síntesis (Original en inglés,1987).

Lyotard, J.F. (2008). La condición postmoderna (Trad. M. Antolín Rato). Madrid: Cátedra (Original en inglés, 1979).

Marfil-Carmona, R. (2015). Análisis de la imagen fotográfica en la comunicación digital de las ONG. Opción, 31(5), 496-515. Disponible en http://produccioncientificaluz.org/ index.php/opcion/article/view/20666 [2017, 3 de septiembre].

Marta-Lazo, C. y Gabelas, J.A. (2016). Comunicación digital. Un modelo basado en el Factor R-elacional. Barcelona: UOC.

Martín Prada, J. (2015). Prácticas artísticas e Internet en la época de las redes sociales (2a. ed.). Madrid: Akal.

Marín Viadel, R. (2003). Aprender a dibujar es aprender a vivir. En R. Marín Viadel (Coord.), Didáctica de la Educación Artística (pp. 3-51). Madrid: Pearson.

Marín Viadel, R. (2011). La investigación en Educación Artística. Educatio Siglo XXI, 29(1), 211-230. Universidad de Murcia. Disponible en http://hdl.handle.net/10201/27182 [2017, 29 de agosto]. 
Marina, J.A. (1993). Teoría de la inteligencia creadora. Barcelona: Anagrama.

McLaren, P. y J.L. kincheloe, (eds.). (2008). Pedagogía crítica. De qué hablamos, dónde estamos (Trad. M. Serrano Larraz). Barcelona: Graó.

Mirzoeff, N. (2016). Cómo ver el mundo. Una nueva introducción a la cultura visual (Trad. P. Hermida Lazcano). Barcelona: Paidós.

Mitchell, W.J. (2009). Teoría de la imagen. Ensayos sobre representación verbal y visual (Trad. Y. Hernández Velázquez). Madrid: Akal (Original en inglés, 1994).

Ornellas, A. (2013). Vídeo social y creación colectiva en un entorno e-learning en educación superior. En D. Aranda, A. Creus y J, Sánchez-Navarro (eds.), Educación, medios digitales y cultura de la participación (pp. 177-195). Barcelona: UOC.

Orozco, G. (1994). Al rescate de los medios. México: Fundación Manuel Buendía Universidad Iberoamericana.

Pons, A. (2014). El desorden digital: guía para historiadores y humanistas. Madrid: Siglo XXI.

Roldán, J. (2011). El mercado de la caridad. Las imágenes de la infancia en la publicidad (solidaria) de las Organizaciones No Gubernamentales. En R. Marín Viadel (Coord.), Infancia, mercado y Educación Artística (pp. 141-158). Málaga: Aljibe.

Roldán, J. y Marín Viadel, R. (2012). Metodologías artísticas de investigación en educación. Málaga: Aljibe.

Rorty, R. (1989). La filosofía del espejo y la naturaleza (Trad. J. Fernández Zulaica). Madrid: Cátedra (Original en inglés, 1979).

Salido López, P. V. (2015). Nuevas tecnologías, universidad y educación artística: el diseño de webquests con rúbricas de evaluación en la formación de formadores. Edutec-e. Revista Electrónica de Tecnología Educativa, (52), 1-10. Disponible en http://www.edutec.es/ revista/index.php/edutec-e/article/view/308/pdf_46 [2017, 2 de septiembre].

Saura Pérez, A. (2013a). E@: red social para la educación artística abierta y a distancia, para la formación continua del profesorado. Estudios sobre el Mensaje Periodístico, 19, 459468. http://dx.doi.org/10.5209/rev_ESMP.2013.v19.42053

Saura Pérez, A. (2013b). Proyecto Exposiciones enREDadas: El enmascaramiento artístico como estrategia metodológica para el desarrollo de competencias profesionales. Historia y comunicación social, 18, 369-383. http://dx.doi.org/10.5209/rev_HICS.2013.v18.44335

Scolari, C. (2008). Hipermediaciones: Elementos para una Teoría de la Comunicación Digital Interactiva. Barcelona: Gedisa.

Sedeño Valdellós, A. (2012). Cine social y autoría colectiva: prácticas de cine sin autor en España. Razón y palabra, 80. Disponible en http://www.razonypalabra.org.mx/N/N80/ M80/11_Sedeno_M80.pdf [2017, 4 de septiembre].

THATCAMP (Non-conférence sur les digital humanities) (2010). Manifiesto por unas humanidades digitales (Trad. Marin Dacos). [Recurso electrónico] Disponible en http:// tcp.hypotheses.org/487 [2017, 2 de septiembre].

Toffler, A. (1979). La tercera ola (Trad. A. Martín). Barcelona: Plaza \& Janés. 